\title{
Bioabsorbable struts made from poly-L-lactide and their application for treatment of chest deformity
}

\begin{abstract}
Poly-L-lactide, a polymer of lactic acid, shows slow degradation in living tissue. Poly-L-lactide plate of high molecular weight maintains more than $90 \%$ of its initial mechanical properties for more than 3 months after implantation. Using struts made from poly-L-lactide plate, we performed chest wall reconstruction in 56 patients: for postoperative chronic sternal dehiscence in 23 and sternal elevation for pectus excavatum in 33 cases. The postoperative external appearances of the anterior chest were improved in comparison with the preoperative state in all cases. The internal features were evaluated by computed tomographic scan. Neither postoperative wound infection nor respiratory complication was observed, and no tendency for regression of the anterior chest occurred in any of the patients. In 3 of 56 cases $(5.4 \%$; one in the sternal dehiscence group and two in the pectus excavatum group), it was necessary to remove part of the strut because of overgrowth of granulation tissue around the implanted material after 4,12 , and 13 postoperative months, respectively. In the pectus excavatum group, the computed tomographic evaluations showed that poly-L-lactide strut maintained sufficient strength to support the thoracic wall 5 months after implantation. These findings suggest that the bioabsorbable poly-L-lactide strut is a promising material for surgical treatment of chest deformity. (J THORAC Cardiovasc Surg 1994;108:162-8)
\end{abstract}

T. Matsui, MD, M. Kitano, MD, T. Nakamura, MD, ${ }^{\mathrm{a}}$ Y. Shimizu, MD, ${ }^{\mathrm{a}} \mathrm{S}-\mathrm{H}$. Hyon, PhD, ${ }^{\mathrm{a}}$ and

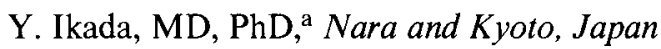

$\mathrm{N}$ umerous surgical techniques have been described for the repair of chest wall deformities. Among them, the sternal elevation method of Ravitch ${ }^{1}$ appears to be in wide use for pectus excavatum, ${ }^{2}$ but for severe and wide asymmetric deformity, satisfactory correction cannot be expected. Several alternative operations with the use of temporary struts or bars are therefore advocated. With regard to the materials used for these struts, metal (A-O plate $)^{3}$ or $\operatorname{resin}^{4}$ have been used. However, the former must be subsequently removed, and the latter may impair growth of the chest wall if not extracted. Poly-L-lactide ( $\mathrm{P}$-L-LA) plate is made of a purified polymer of L-lactide

From the Department of Thoracic Surgery, Tenri Hospital, Nara; and the Research Center for Biomedical Engineering, Kyoto University, ${ }^{\text {a }}$ Kyoto, Japan

Received for publication Aug. 5, 1993.

Accepted for publication Nov. 29, 1993.

Address for reprints: T. Nakamura, MD, Research Center for Biomedical Engineering, Kyoto University, 53 Kawahara-cho, Shogoin, Sakyo-ku, Kyoto 606, Japan.

*Arbeitsgemeinshaft für Osteosynthesefragen.

Copyright 1994 by Mosby-Year Book, Inc.

$0022-5223 / 94 \$ 3.00+0 \quad 12 / 1 / 53446$ that gradually degrades to the monomer by hydrolysis under humid conditions and is absorbed by the body. It has therefore been studied extensively for possible biomedical application, ${ }^{6}$ and polylactides are now widely used clinically as bioabsorbable suture materials. The present article describes our clinical experience with P-LLA plate for chest wall deformity and discusses its clinical usefulness, focusing on surgical procedures and postoperative complications.

\section{Patients and methods}

Material. P-L-LA, with a molecular weight of $1.8 \times 10^{5}$, is fabricated from L-lactide monomer by ring-opening polymerization as described before ${ }^{6}$ (Fig. 1). This P-L-LA is a semicrystalline polymer with a computed tomography (CT) number of 400 to 500 Housefield Units (H.U.) and a glass transition temperature of $57^{\circ} \mathrm{C}$. When the plate is heated up to $60^{\circ} \mathrm{C}$, it becomes soft and its shape can be changed as desired. At body temperature, the shape is stable. Unreacted monomer and contaminants in the polymer were removed by the precipitation method. ${ }^{7}$ Square plates $(18 \mathrm{~cm} \times 18 \mathrm{~cm})$ with thicknesses of 2.0, 2.5, and $3.0 \mathrm{~mm}$ were made from P-L-LA by a compression molding technique with a hot press. The P-L-LA plates maintain their initial mechanical properties for the first 3 months and then gradually dissolve into the monomer, being absorbed completely by the tissue within 3 years after implan- 


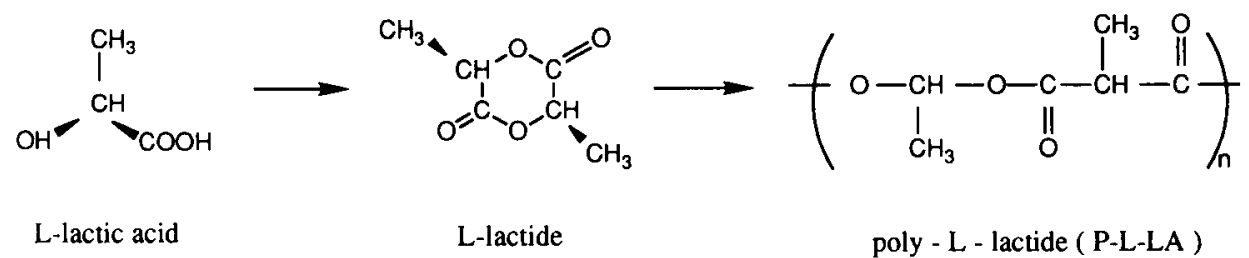

Fig. 1. Chemical structure of P-L-LA.
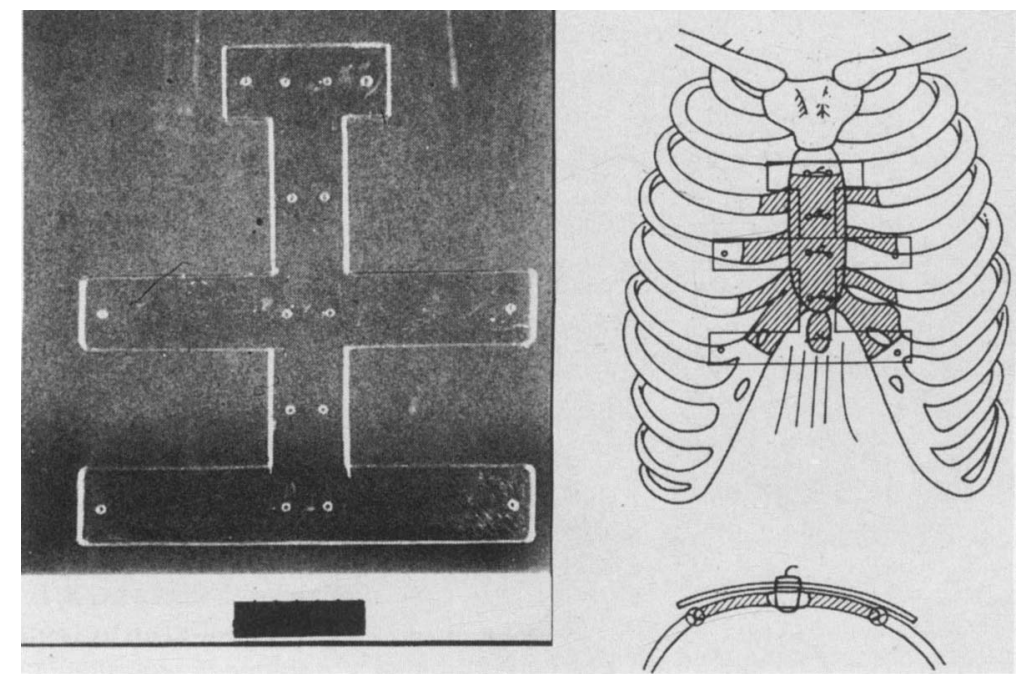

Fig. 2. P-L-LA plate for funnel chest. The relation between the P-L-LA plate and the anterior chest (right). The width of the plate is slightly longer than the plastron (oblique line).

tation. ${ }^{6}$ P-L-LA struts were cut out from the plates. Each strut had one longitudinal and three or four transverse bars (Fig. 2). The thickness was chosen according to the patient's age and degree of deformity in each case. Sterilization of the implants was done with ethylene oxide gas.

A total of 56 patients underwent chest wall reconstruction with the use of these P-L-LA plates. Twenty-three had poststernotomy sternal dehiscence (SD group), and 33 had pectus excavatum (PE group).

In the SD group, the primary illness was ventricular septal defect (VSD) in all cases. In these 23 patients (seven were male and 16 were female), although the clinical courses after operation for VSD were good and no wound infection occurred, deformity of the anterior chest wall caused by sternal dehiscence had developed gradually; the left half of the residual sternum overlapped the right in 14 patients, right to left overlapping occurred in one, and symmetric retraction at the mid-sternal line occurred in eight. Therefore, chest wall reconstructions were performed. The patients ranged in age from 1 year and 10 months to 19 years, with a mean of 8.8 years. At the first operation, the sternum was closed with nonabsorbable suture $(2-0$ Ethibond; Ethicon, Inc., Somerville, N.J.) in 21 patients; stainless steel wire was used in two patients. The second operations were performed at least 1 year after sternotomy in all cases.

In the PE group, 31 patients were male and two were female, ranging in age from 4 years to 38 years with a mean of 11.2 years. Twenty-six cases were of the symmetric type, and seven were of the asymmetric type. Because none of these patients had marked impairment of cardiorespiratory function, the corrective procedures were performed for cosmetic reasons.

Our sternal elevation procedure was as follows: a median skin incision was made, excessive portions of the rib cartilage were excised (commonly from the third to the sixth or seventh rib), and the sternum was transected at the intercostal space where the deformity began (level of the second or third rib). If necessary, sternal wedge osteotomy was added anteriorly or posteriorly, and, after insertion of a small cartilage fragment, the osteotomy site was ligated with stainless steel wires or heavy braided silk sutures to make it flat. The plastron was then fixed to the anterior chest. The P-L-LA strut was shaped to match the concavity of chest and was fixed to the anterior chest with several stainless steel wires (Fig. 2, Fig. 3,B). It was possible to decrease the dead space between the strut and the anterior chest by compression of the strut with a hot towel heated up to $60^{\circ} \mathrm{C}$.

In the PE group, preoperative and postoperative CT scans were taken in all cases. At the level of the most depressed part of the chest wall, the distance between the beginning points of the retraction $\left(l_{0}\right)$ and the distance from the anterior surface of the sternum to the bottom $\left(\mathrm{d}_{0}\right)$ were measured (Fig. 4). On the basis of these $l_{0}$ and $d_{0}$ values, the retraction index was calculated to express the degree of deformity as follows: retraction index $=\mathrm{d}_{0} / \mathrm{l}_{0} \times 100$. Postoperative evaluation was done in the same manner at the same level in each case. In some cases, CT 

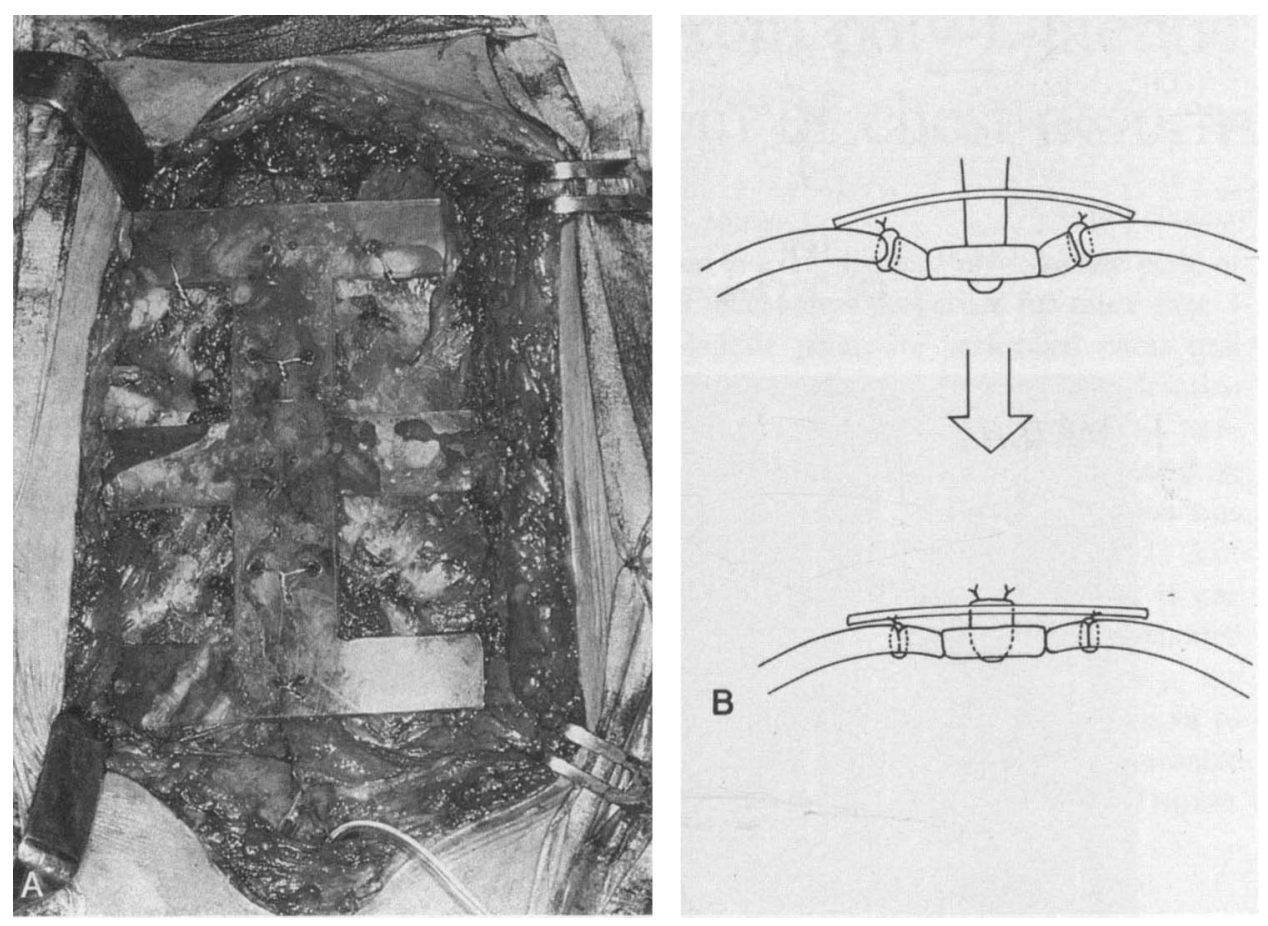

Fig. 3. A, The appearance of anterior chest when the P-L-LA plate was fixed with steel wire. B, Even if the plastron is slightly retracted after resection of excessive ribs and costal cartilage, it can be pulled up to a natural position with a P-L-LA plate of greater curvature and a steel wire pulled through it, resulting in reduction of any dead space.

scans were taken at 5 months and 11 months after the operation.

The study was approved by the ethics committee of our hospital, and all patients gave informed consent before operation and examination.

\section{Results}

The postoperative appearance of the anterior chest was much improved in all cases, becoming almost flat with a good external profile. No regression of the anterior chest occurred in any patient.

CASE 1 . The patient was a girl 1 year and 10 months of age (SD group). After she had undergone patch closure operation for VSD, protrusion became gradually obvious on the left anterior chest wall. Chest wall reconstruction was performed 4 years after the first operation for VSD. At the second operation, the left side of the sternum overlapped the right, where pseudoarthrosis (nonunion) had formed (Fig. 5, a). After trimming, the bilateral sternal margins were connected with stainless steel wires, and a P-L-LA strut was fixed onto the anterior chest wall with stainless steel wires to stabilize the sternum. The postoperative appearance became good, and, even at 6 months after the operation, no tendency for regression was found (Fig. $5, b)$.

CASE 2. The patient was a boy 14 years of age (PE group) with severe pectus excavatum. At operation, the plastron was first formed by resection of excessive ribs and costal cartilage and by cutting across the sternum at the level of the third intercostal space. After trimming of the retracted portion of the sternum, the plastron was stayed to the thoracic wall. The P-L-LA plate was then fixed on the plastron with stainless steel wire to pull it up (Fig. 3, $A$ ). This plate had one longitudinal and three transverse bars. The transverse bars were curved more sharply than the chest wall because the slightly greater curvature of the strut allowed the elastic P-L-LA strut to pull up the plastron. The curved P-L-LA plate gave the reconstructed chest wall a natural curve, and firm fixation with stainless steel wire decreased the likelihood of possible complications by reducing any dead space containing exudate (Fig. 3, B). Postoperative CT showed no retraction of the anterior chest wall. One year after the operation, no change was observed in the appearance of the anterior chest wall (Fig. 6).

Neither postoperative wound infection nor severe respiratory complication occurred in any patient. Even in cases observed for more than 4 years after the operation, no regression to the preoperative state occurred. However, in three of the 56 cases $(5.4 \%)$, partial removal of the P-L-LA strut was required because of skin opening caused by overgrowth of granulation tissue around the strut. One of these cases was in the SD group, and two were in the PE group, occurring after 4, 11, and 13 postoperative months, respectively. In the patients who underwent reoperation after 11 and 13 months, many fragile 
Volume 108, Number 1

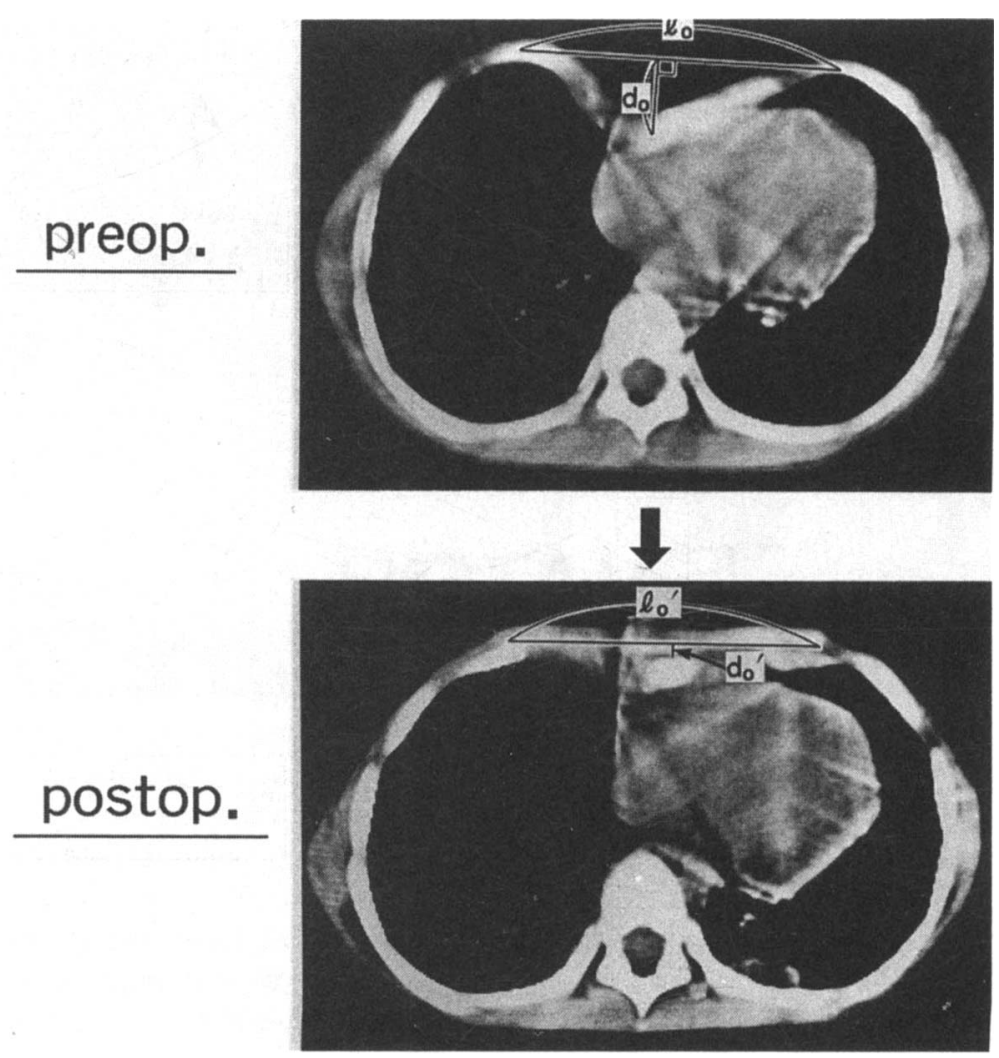

Fig. 4. Method used for calculation of the retraction index. preop., Before the operation; postop., after the operation.

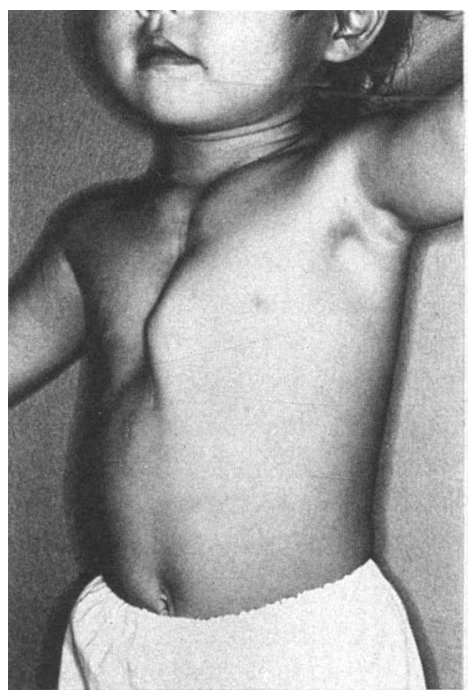

a.

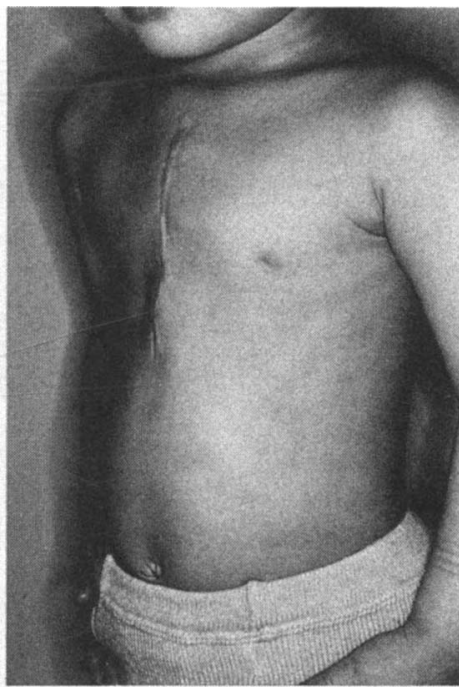

b.

Fig. 5. a, Preoperative external appearance of a patient in the SD group. b, External appearance of the same patient 6 months after operation. 


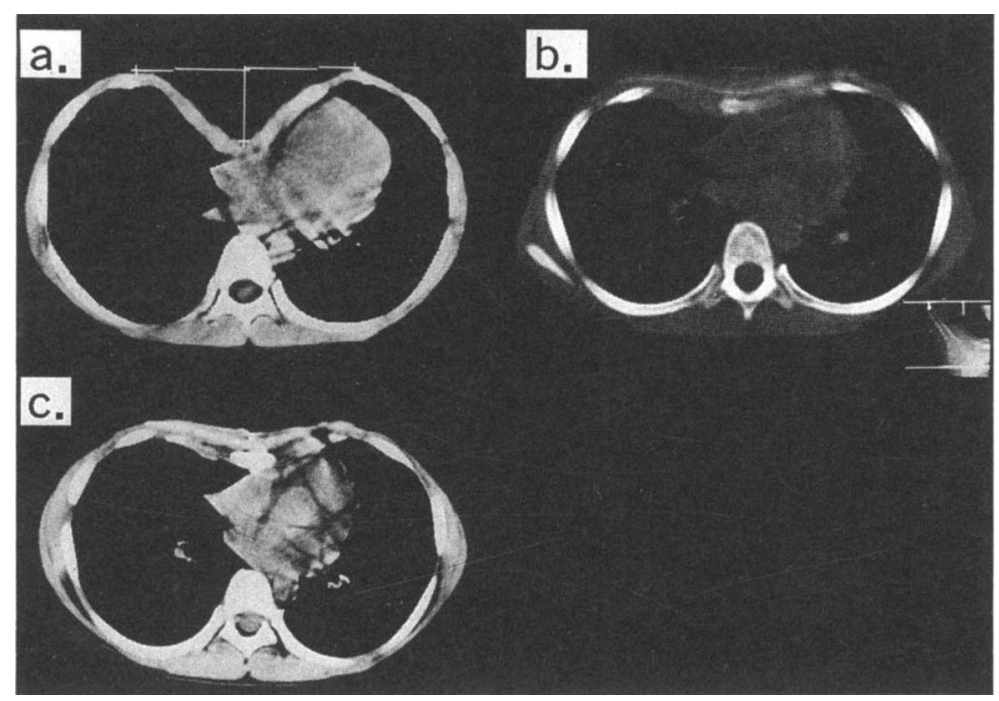

Fig. 6. CT scan in the PE group. In the preoperative state (a), retraction index was 33. Immediately after operation (b), retraction index was improved to 2.87. Even 1 year after operation (c), the index was 2.98 .

Table I. Patient profiles and results

\begin{tabular}{lcc}
\hline & SD group & PE group \\
\hline No. of cases & 23 & 33 \\
Sex (M/F) & $7 / 16$ & $31 / 2$ \\
Mean age (yr) & $1-19(8.8)$ & $4-38(11.2)$ \\
Retraction index & & \\
$\quad$ Preoperative & & $31.4 \pm 7.03$ \\
$\quad$ Postoperative (2 wk) & & $2.64 \pm 0.48$ \\
$\quad$ Postoperative $(5 \mathrm{mo})$ & & $3.24 \pm 1.08(n=14)$ \\
No. of complications of & 1 & 2 \\
$\quad$ skin opening and & & \\
$\quad$ partial removal of & & \\
$\quad$ P-L-LA & & \\
Regression of the & None \\
$\quad$ anterior chest & & \\
\hline
\end{tabular}

fragments of P-L-LA struts were found in the granulation tissue. After reoperation, the wound healed completely and the clinical course was uneventful.

In the PE group, the preoperative retraction index was $31.4 \pm 7.03$, and the postoperative retraction index was $2.64 \pm 0.48$, indicating significant improvement $(p<0.05)$. The retraction index at 5 months after the operation, evaluated in 14 cases, was $3.24 \pm$ 1.08 (Table I). This result indicates that the P-L-LA strut maintained sufficient strength to support the thoracic wall during this period. The above surgical procedures gave an excellent cosmetic result even for patients with asymmetry, which had been difficult to correct by the sternal turnover method we had used previously.

\section{Discussion}

A variety of methods for surgical correction of chest deformity have been introduced, and these are broadly classified into two types: sternal turnover and sternal elevation. For both methods, the recurrence of chest depression is the major long-term complication and is considered to be caused by insufficient fixation of the elevated sternum and deterioration of blood supply. ${ }^{8}$ Controversy still exists regarding the presence or absence of a significant effect of the deformity on cardiorespiratory function and whether repair of pectus excavatum alters cardiorespiratory function. Wynn and associates ${ }^{9}$ group compared an operation group and a nonoperation group of adolescent patients and concluded that surgery had no physiologically significant effect on the cardiorespiratory response to exercise. Kaguraoka and associates ${ }^{10}$ concluded that both sternal turnover and sternal elevation are optimal for maintenance but not for improvement of respiratory function.

The sternal elevation method developed by Ravitch ${ }^{1}$ appears to be in greatest use, being relatively noninvasive and producing a natural result, even in children. However, at the end of the operation, the loss of rigid support of the anterior chest results in mild to moderate paradoxic motion of the sternum with respiration until the chest wall begins to become firm after 10 to 14 days. Therefore several alternative operations are advocated in which the sternum is provided with temporary postoperative support by a metal or resin strut. However, several problems remain to be resolved, the major one being removal of the strut. Nakanishi and associates ${ }^{11}$ reported a modification 
of the Ravitch technique using a living rib strut with a vascular pedicle, and the results were all satisfactory. However, this approach requires resection of the right fifth rib, and the thoracic cavity must be opened.

In the internal support operation, the metal strut is removed after 4 to 6 months, frequently under local anesthesia. ${ }^{4}$ In Ravitch's method, the chest wall begins to become firm by 10 to 14 days, and it is well healed in 6 to 8 weeks in most patients. With respect to the previously mentioned considerations, mechanical stenting support is required for only 2 to 3 months after operation. In this study, we applied high-molecular-weight P-L-LA, which shows slow degradation. Chest wall reconstruction was performed in 56 patients with the use of struts made of this material, and the postoperative appearance was much improved in comparison with the preoperative state. In three patients, removal of the strut was necessitated because of overgrowth of granulation tissue around the P-L-LA. In all three cases, the thickness of the plate was $2.0 \mathrm{~mm}$, and at removal all the struts were broken into pieces. The overgrowth of granulation tissue in these three cases was thought to be due to the fact that the applied P-L-LA was not thick enough to support the underlying severe deformity; this deficit caused the P-L-LA strut plate to break down early after implantation, resulting in mechanical stimulation of the surrounding tissue by fragments of the strut and acceleration of the liberation of lactate monomer, thus inducing an excessive tissue reaction. The broken fragments of P-L-LA sample removed 4 months after implantation had sharp edges. The bending-breaking strength of high-molecularweight P-L-LA used for screws or bone plates is about 200 $\mathrm{MPa} / \mathrm{cm}^{2}$, which is similar to or higher than that of bone cortex (120 to $210 \mathrm{MPa}$ ) and was maintained for 3 months after implantation. ${ }^{12}$ The mechanical toughness of a P-L-LA plate depends on its thickness. In view of our clinical experiences, we now consider that a thickness of $2.5 \mathrm{~mm}$ or more is sufficient for chest struts.

In late thoracic deformities in children caused by poststernotomy sternal dehiscence, correction is not easy because of asymmetric growth of the ribs and because the sternum is often completely absorbed and absent at second operation. In such cases, the P-L-LA strut would be a valid alternative for reinforcing and stabilizing the chest wall, and as Sargent and associates ${ }^{9}$ reported, rigid fixation of the sternum would result in earlier union with primary osseous healing.

The sternal turnover method was first reported by Scheer. ${ }^{13}$ Previously we had used sternal turnover with a muscle pedicle for pectus excavatum. However, the sternal turnover method also had some disadvantages, particularly in adult patients: interruption of blood supply to the plastron caused by twisting of the pedicle, difficulty of correction for the wide and asymmetric type, and protrusion of the retracted portion in severe cases. Using bone and bone marrow scanning, Watanabe and associates ${ }^{14}$ indicated that the strut method resulted in the least degree of functional impairment, whereas in the sternal turnover technique, although preservation of blood supply to the plastron with a muscle pedicle produced more favorable results than did the technique without a muscle pedicle, incidental impairment of bone and bone marrow function occurred for some months after operation. With the conventional sternal elevation method, metal or resin struts have been widely used. However, the former must be subsequently removed, and the latter may impair the growth of the chest wall if not extracted. In contrast, P-L-LA plates do not need to be extracted and do not impair the growth of the chest wall because they are absorbed. Furthermore, struts can be easily molded or bent even in the operating room and produce little tissue reaction. Moreover, implanted metals often produce artifacts on $\mathrm{CT}$ or magnetic resonance images, making postoperative follow-up difficult. The CT number of P-L-LA is about 400 H.U., which is lower than that of bone tissue (between that of bone and that of soft tissue). P-L-LA produces no magnetic interference with magnetic resonance imaging. Thus, P-L-LA of high molecular weight has ideal characteristics for use in struts, compensating for the defects of the other two types. P-L-LA struts seem to be indicated for cases that are difficult to treat by the conventional sternal turnover method, in addition to cases of postoperative sternal dehiscence. With regard to the operation method for chest deformity, as Humphreys and Jaretzki ${ }^{15}$ suggested, better objective methods of evaluation over many years are needed to judge the value of any product, and therefore we intend to continue applying this technique and carrying out long-term follow-up.

\section{REFERENCES}

1. Ravitch MM. The operative treatment of pectus excavatum. Ann Surg 1949:129:429-44.

2. Bryant LR, Morgan CV. Chest wall pleura, lung, and mediastinum. In: Schwartz SI, ed. Principles of surgery. New York: McGraw-Hill, 1983;636-42.

3. Gotzen L, Dragojevic D. Funnel chest correction by use of AO implants and instruments. Thorac Cardiovasc Surg 1979;27:61-4.

4. Rehbein F, Wernicke HH. Operation der Trichterbrust. Z Orthop 1958;89:475-81.

5. Bos RRM, Boering G, Rozema FR, et al. Resorbable poly (L-lactide) plates and screws for the fixation of zygomatic fractures. J Oral Maxillofac Surg 1987;45: 751-3. 
6. Nakamura T, Hitomi S, Watanabe S, et al. Bioabsorption of polylactides with different molecular properties. $\mathrm{J}$ Biomed Mater Res 1989;23:1115-30.

7. Hyon S-H, Jamshidi K, Ikada Y. Melt spinning of poly-Llactide and hydrolysis of the fiber in vitro. In: Shalaby $W$, Hoffman AS, eds. Polymers as biomaterials. New York: Plenum Publishing, 1984;51-65.

8. Sargent LA, Seyfer AE, Hollinger J, Hinson RM, Graeber GM. The healing sternum: a comparison of osseous healing with wire versus rigid fixation. Ann Thorac Surg 1991; $52: 490-4$

9. Wynn SR, Driscoll DJ, Ostrom NK, et al. Exercise cardiorespiratory function in adolescents with pectus excavatum. J Thorac Cardiovasc Surg 1990;90:41-7.

10. Kaguraoka H, Ohnuki T, Itaoka T, Kei J, Yokoyama M, Nitta $S$. Degree of severity of pectus excavatum and pulmonary function in preoperative and postoperative periods. J Thorac Cardiovasc Surg 1992;104:1483-8.
11. Nakanishi Y, Nakajima T, Sakakibara A, Nishiyama T. A vascular rib strut technique for funnel chest correction. $\mathrm{Br}$ J Plast Surg 1992;45:364-6.

12. Matsusue Y, Yamamuro T, Oka M, Shikinami Y, Hyon $\mathrm{SH}$, Ikada $\mathrm{Y}$. In vitro and in vivo studies on bioabsorbable ultra-high-strength poly(L-lactide) rods. J Biomed Mater Res 1992;26:1553-67.

13. Scheer R. Über eine neue Methode der chirurgischen Behandlung der Trichterbrust. Die "gestielt Umwendungsplastik." Chirurgie 1957;28:312-4.

14. Watanabe $\mathrm{Y}$, Magara $\mathrm{T}$, Kobayashi $\mathrm{H}$, et al. Bone and bone marrow function of reconstructed chest wall after surgical correction of pectus excavatum. J Jpn Assoc Thorac Surg 1984;32:349-55.

15. Humphreys GH, Jaretzki A. Pectus excavatum: late results with and without operation. J THORAC CARDIOVASC SURG 1980;80:686-95. 